Article

\title{
Energy Use Efficiency Past-to-Future Evaluation: An International Comparison
}

\author{
Chia-Nan Wang ${ }^{1}$, Thi-Duong Nguyen ${ }^{1, *}$ and Min-Chun $\mathrm{Yu}^{2}{ }^{2}$ \\ 1 Departments of Industrial Engineering and Management, National Kaohsiung University of Sciences and \\ Technology, Kaohsiung 80778, Taiwan; cn.wang@hi-p.com \\ 2 Departments of Business Administration, National Kaohsiung University of Sciences and Technology, \\ Kaohsiung 80778, Taiwan; yminchun@cc.kuas.edu.tw \\ * Correspondence: duongyennguyen@gmail.com; Tel.: +886908566040
}

Received: 19 September 2019; Accepted: 6 October 2019; Published: 8 October 2019

\begin{abstract}
Despite the many benefits that energy consumption brings to the economy, consuming energy also leads nations to expend more resources on environmental pollution. Therefore, energy efficiency has been proposed as a solution to improve national economic competitiveness and sustainability. However, the growth in energy demand is accelerating while policy efforts to boost energy efficiency are slowing. To solve this problem, the efficiency gains in countries where energy consumption efficiency is of the greatest concern such as China, India, the United States, and Europe, especially, emerging economies, is central. Additionally, governments must take greater policy actions. Therefore, this paper studied 25 countries from Asia, the Americas, and Europe to develop a method combining the grey method (GM) and data envelopment analysis (DEA) slack-based measure model (SMB) to measure and forecast the energy efficiency, so that detailed energy efficiency evaluation can be made from the past to the future; moreover, this method can be extended to more countries around the world. The results of this study reveal that European countries have a higher energy efficiency than countries in Americas (except the United States) and Asian countries. Our findings also show that an excess of total energy consumption is the main reason causing the energy inefficiency in most countries. This study contributes to policymaking and strategy makers by sharing the understanding of the status of energy efficiency and providing insights for the future.
\end{abstract}

Keywords: energy efficiency; data envelopment analysis; super-SBM; grey model; energy consumption

\section{Introduction}

In recent decades, energy is considered as the basic input of numerous productions; therefore, energy is one of the key indicators of economic growth. According to Barney et al. [1], energy consumption is the central operation of modern economies and drives economic productivity as well as industrial development with at least half of industrial growth based on energy consumption [1]. However, consuming energy emits greenhouse gases, which are directly related to global warming and climate change as well as environmental pollution [2]. According to International Energy Agency (IEA) [3], the global energy-related carbon dioxide $\left(\mathrm{CO}_{2}\right)$ emissions in 2018 increased by $1.7 \%$ and reached its historic highest growth rate since 2013 with a total amount of $\mathrm{CO}_{2}$ emissions of 33.1 gigatons (Gt), which is equal to $70 \%$ higher than the average increase since 2010.

Despite the many benefits that energy consumption brings to the economy, consuming energy also leads nations to expend more resources on environmental pollution [2]. Therefore, energy efficiency, which has featured in national and international policy for more than 40 years, has been proposed as a solution, namely as a highly effective pathway, to improve the economic competitiveness and sustainability of every economy, lower emissions, reduce energy dependency, and increase the security 
of supply as well as job creation [4]. The idea that energy efficiency should be an important part of government energy policy developed in response to the first oil price crisis in 1973, when reducing energy demand was seen as a route to greater energy security in many developed countries. Thus, energy efficiency is already understood as a means by which to reach a variety of ends and its role in policy making is increasing [5].

According to the IEA report [3], despite the progress on energy efficiency, the growth in energy demand is accelerating. To solve this problem, the efficiency gains in countries where energy consumption efficiency is of the greatest concern such as China, India, the United States, and Europe, especially emerging economies, is central. Additionally, to obtain the targets of environmental protection and economic growth, many countries have been implementing a suite of policies to improve energy efficiency [3]. However, the current policy efforts to boost energy efficiency are slowing down in a time when energy efficiency could deliver significant economic, social, and environmental benefits, but only if governments take greater policy action.

To create efficiency gains, the right policies and greater policy actions are necessary. The throughout energy efficiency evaluation and forecast is helpful in enhancing the understanding of the current status and outlook for the energy efficiency of different economies, which can help in making the right policies to boost energy efficiency. Therefore, focusing on the importance of energy efficiency evaluation in policy making, this study used the top 25 energy consuming countries to develop a method to measure and forecast the energy efficiency, from which a detailed energy efficiency evaluation can be made from the past to the future. Furthermore, this method can be extended to more countries around the world.

Energy efficiency in European countries has always captured the great attention of researchers. Therefore, many previous studies measuring energy efficiency and energy efficiency policies in European countries can be found in the literature [6-16]. Calvet et al. [6] evaluated the environmental performance of the European Union (EU) over the period 1993-2010. In that study, a two-stage DEA analysis was applied to obtain the research objectives. The results of that paper indicated that the eco-efficiency indicator has improved over the last two decades; however, in the case of traditional indicators such as $\mathrm{CO}_{2}$ emissions, the abatement opportunities are still remarkable.

Energy efficiency in Asia, where there are many emerging economies, is the hot issue for policymakers. However, not many studies have evaluated the energy efficiency of Asian countries except in those related to China [17-21]. China is the largest country in terms of energy consumption and related-energy $\mathrm{CO}_{2}$ emissions, which is why energy efficiency is one of China's greatest concerns. Yang et al. [17] measured the energy efficiency of 30 Chinese provinces in 2013 and 2014 by applying the DEA Super-SBM model and found that China's overall energy efficiency was low and had decreased when taking the undesirable outputs into consideration.

The attention to energy efficiency has not been given in Europe and China, but also in other regions and cross-countries, as shown in the study by Zhou et al. [22], who measured the energy efficiency of the Asia-Pacific Economic Cooperation region (APEC) and Guo et al. [23], who evaluated the energy efficiency of Organisation for Economic Co-operation and Development (OECD) countries. Studies measuring the energy efficiency of different countries from different regions can also be found in the literature, for example, Zhang et al. [24] investigated the energy efficiency of 23 different developing countries; Pang et al. [25] evaluated the environmental efficiency of different countries; Wang et al [26] used the DEA super-SBM model and Malmquist productivity index (MPI) to measure the energy efficiency and efficiency improvement of 17 countries; and Wang et al. [27] measured the energy efficiency of the top 25 countries by $\mathrm{CO}_{2}$ emissions in 2017.

Despite many studies in this field, no study forecasting the energy efficiency cross-country was found in the literature. Therefore, our study is expected to be the first empirical study to use a hybrid model to measure and forecast energy efficiency, which sheds new light in the literature for a new research aspect of energy efficiency. The rest of this paper is organized as follows. Section 2 describes the research methodology measuring and forecasting energy efficiency. Section 3 presents the detailed empirical results. Section 4 presents the discussion and the conclusions drawn from the research. 


\section{Materials and Methods}

In this section, the hybrid method is introduced to evaluate the energy efficiency of different countries from the past to the future. First, the DEA slack-based measure model (SBM) is applied to obtain the efficiency of the selected countries. Second, the grey model GM $(1,1)$ is used for forecasting the values of the inputs and outputs over future period. Finally, the DEA SBM is employed again to evaluate efficiency in future years, then a comparison can be made between the results in the past and future.

Due to the presence of undesirable outputs in this study, the SBM model, which can deal with bad outputs, is the best choice, while the grey model GM $(1,1)$ is a suitable forecast model for this study because it does not require a large amount of input data.

\subsection{Grey Model GM $(1,1)$}

In recent years, the grey prediction model has been applied in many research fields thanks to its popularity and computational efficiency. GM $(1,1)$ represents the time-series prediction model in the first order of placing a variable [28], and is the most popular forecast model used by scientists because a part of GM $(1,1)$ can deliver a relatively high predictive rate while not requiring an entire set of historical data except for a small amount of input data (at least four). This is the reason why GM $(1,1)$ is suitable for almost all fields and different areas.

In this study, as the period of the past data collection was only five years, the selection of this model to predict future results is perfectly appropriate.

The model structure of GM $(1,1)$ is described as follows:

Denote the original form of GM $(1,1)$ as in Equation (1)

$$
x^{(0)}=\left(x^{(0)}(1), \ldots, x^{(0)}(n)\right), n \geq 4
$$

The one-time accumulated generating operation (1-AGO) of the original sequence $x^{(0)}$ is defined as:

$$
x^{(1)}=\left(x^{(1)}(1), \ldots, x^{(1)}(n)\right), n \geq 4
$$

Consider Equation (3) as the original form of the GM $(1,1)$ model, where the symbol GM $(1,1)$ stands for the first order grey model in variables.

$$
x^{(0)}(k)+a x^{(1)}(k)=b
$$

Consider Equation (4) as the basis form of this model.

$$
x^{(0)}(k)+a z^{(1)}(k)=b, k=1,2, \ldots, n
$$

where $z^{(1)}(k)=0.5 x^{(1)}(k)+0.5 x^{(1)}(k-1), k=1,2, \ldots, n$. a, b are the coefficients; in grey system theory terms, a is said to be a developing coefficient and b the grey input; and $x^{(0)}(k)$ is the grey derivative that maximizes the information density for a given series to be modeled.

According to the least square method, we have $\hat{\mathbf{a}}=\left[\begin{array}{l}\boldsymbol{a} \\ \boldsymbol{b}\end{array}\right]=\left(B^{T} B\right)^{-1} B^{T} Y_{N}$.

Therefore,

$$
\mathrm{B}=\left[\begin{array}{cc}
-z^{1}(2) & 1 \\
-z^{1}(3) & 1 \\
\vdots & \vdots \\
-z^{1}(n) & 1
\end{array}\right] Y_{N}=\left[\begin{array}{c}
x^{(0)}(2) \\
x^{(0)}(3) \\
\vdots \\
x^{(0)}(n)
\end{array}\right]
$$

Here, $\mathbf{B}$ is called a data matrix. 
By considering the following equation $d x^{(1)} / d t+a x=b$ as a shadow for $x^{(0)}(k)+a z^{(1)}(k)=b$, then the response equations for GM $(1,1)$ are as follows:

$$
\begin{gathered}
\hat{x}^{(1)}(k+1)=\left(\left(x^{(0)}(1)-\frac{b}{a}\right) e^{-a k}+\frac{b}{a}\right), k=1,2,3, \ldots, n . \\
\hat{x}^{(0)}(k+1)=\hat{x}^{(1)}(k+1)-\hat{x}^{(1)}(k)
\end{gathered}
$$

\subsection{DEA Slack-Based Measure Model}

With the presence of undesirable outputs, there is one popular DEA model that can deal with this problem called Slack-based measure model (SBM), which was proposed by Tone in 2003 [29] and extended the SBM model proposed in 2001 by Tone [30]. In this study, we followed the equations proposed by Tone (2003) and are detailed as follows.

Suppose that $\mathrm{n}$ represents the number of decision-making units (DMUs) and each DMU has inputs, desirable outputs, and undesirable outputs.

Let us decompose the output matrix $Y$ into $\left(Y^{\mathrm{g}}, \mathrm{Y}^{\mathrm{b}}\right)$, where $\mathrm{Y}^{\mathrm{g}}, \mathrm{Y}^{\mathrm{b}}$ denote good (desirable) and bad (undesirable) output matrices, respectively. For a DMU $\left(x_{0}, y_{0}\right)$, the decomposition is denoted as $\left(x_{\mathrm{o}}, y_{\mathrm{o}}^{\mathrm{g}}, y_{0}^{\mathrm{b}}\right)$.

The production possibility set is defined by:

$$
\mathrm{P}=\left\{\left(x, y^{\mathrm{g}}, y^{\mathrm{b}}\right) \mid x \geq \mathrm{X} \lambda, y^{\mathrm{g}} \leq \mathrm{Y}^{\mathrm{g}} \lambda, y^{\mathrm{b}} \geq \mathrm{Y}^{\mathrm{b}} \lambda, \mathrm{L} \leq \mathrm{e} \lambda \leq \mathrm{U}, \lambda \geq 0\right\}
$$

where $\lambda$ is the intensity vector while $\mathrm{L}$ and $\mathrm{U}$ are the lower and upper bounds of the intensity vector, respectively. Then, a DMU $\left(x_{0}, y_{0}^{\mathrm{g}}, y_{\mathrm{o}}^{\mathrm{b}}\right)$ is efficient in the presence of bad outputs, if there is no vector $\left(x, y^{\mathrm{g}}, y^{\mathrm{b}}\right) \in \mathrm{P}$ such that $x_{\mathrm{o}} \geq x, y_{\mathrm{o}}^{\mathrm{g}} \leq y^{\mathrm{g}}, y_{\mathrm{o}}^{\mathrm{b}} \geq y^{\mathrm{b}}$ with at least one strict inequality.

In accordance with this definition, we modified the SBM in Tone (2001) as follows.

$$
[S B M] \rho^{*}=\min \frac{1-\frac{1}{m} \sum_{i=m}^{m} S_{i}^{-}}{1+\frac{1}{S_{1} S_{2}}\left(\sum_{r=1}^{S 1} \frac{S_{r}^{g}}{y_{r o}^{g}}+\sum_{r=1}^{S 2} \frac{y_{r}^{b}}{y_{r o}^{b}}\right)}
$$

Subject to

$x_{\mathrm{o}}=X \lambda+S^{-}$

$y_{\mathrm{o}}^{g}=Y^{g} \lambda-s^{g}$

$y_{\mathrm{o}}^{b}=Y^{b} \lambda+S^{b}$

$\mathrm{L} \leq \mathrm{e} \lambda \leq \mathrm{U}$

$S^{-} \geq 0, S^{g} \geq 0, S^{b} \geq 0, \lambda \geq 0$

where vector $S^{-} \in R^{m}$ : excesses in inputs and $S^{b} \in R^{S 2}$ : excesses in bad outputs and $S^{g} \in R^{S 1}$ is the shortage in the good outputs. With the presence of bad outputs, the DMU $\left(x_{0}, y_{0}^{\mathrm{g}}, y_{\mathrm{o}}^{\mathrm{b}}\right)$ is efficient if and only if $\rho^{*}=1$, i.e., $S^{-*}=0, S^{g^{*}}=0$, and $S^{b *}=0$.

\section{Empirical Results}

\subsection{Data Collection}

There are different approaches to energy efficiency in the national and international literature as well as in various scientific disciplines. Traditionally, energy efficiency is defined as the use of energy in an optimum to achieve the same service that could have been achieved using a common less efficient manner [3], however, many opinions have claimed that energy alone cannot produce any economic output; therefore, energy efficiency should be interpreted as the use of non-energy inputs and energy to produce economic desirable outputs while reducing greenhouse gases emissions. Energy efficiency 
can be achieved by meeting the requirements of human, institutional, legal, technical, and financial capacities, or in general, the right energy efficiency policy combines all of the above requirements.

In this study, we followed the concept that using energy along economic inputs can produce desirable economic outputs (i.e., gross domestic production-GDP), however, at the same time, they emit undesirable outputs (i.e., greenhouse gas emissions such as $\mathrm{CO}_{2}$ ). Regarding the economy, labor force and capital stock are two popular indicators where the data are available; therefore, these two economic indicators were selected as the economic inputs while the total energy consumption represented the energy inputs. GDP was selected as the desirable output while $\mathrm{CO}_{2}$ emissions were considered as the undesirable output. Additionally, since no direct source provides data of capital stock, in this study, we used gross capital formation to present capital.

Due to the incomplete data for some countries for 10 years, 25 countries that provided sufficient data were chosen as the sample in this study. Data used in this study were collected from two main sources: the Enerdata Yearbook [31] and data from the World Bank [32]. Since data for 2018 are not available, data from the 10 years between 2008-2017 were used to measure the energy efficiency in the first stage. In the second stage, we used data from 1990 to 2017 to forecast the efficiency for period 2018-2023. The flow of this study is described in Figure 1.

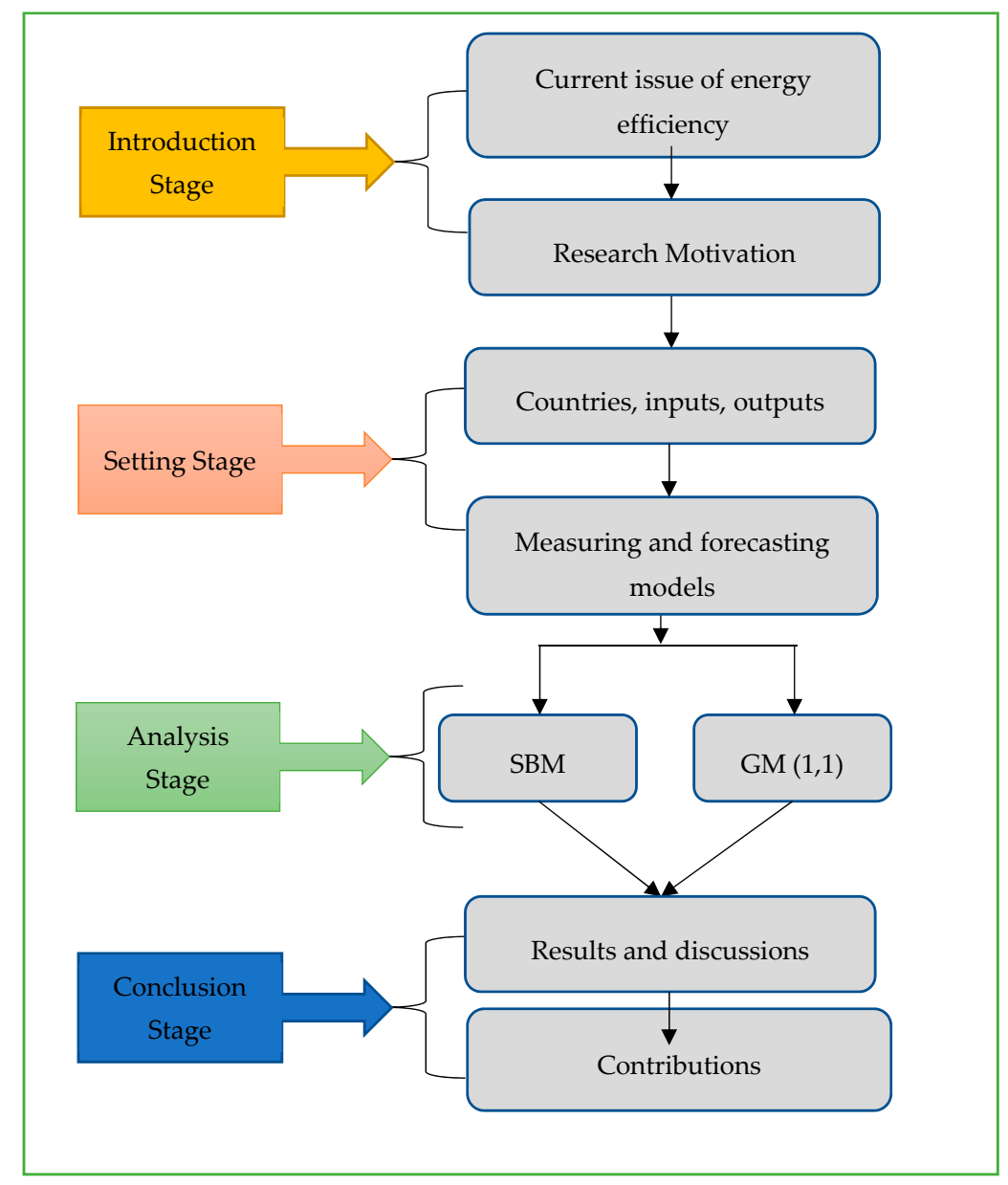

Figure 1. Research flow.

\subsection{Energy Efficiency from 2008 to 2017}

In this stage, DEA-Solver-Pro software was used to measure the energy efficiency through the DEA SBM model. The results obtained from 2008-2017 are shown in Table 1 and the graphical illustration of the average score of each country can be seen in Figure 2. 
Table 1 indicates the low efficiency score of the 25 countries with the average score ranging from the lowest at 0.64 in 2011 to the highest of 0.70 in 2010. As can be observed, the average score for each year from 2008 to 2017 remained stable with insignificant change.

When considering the whole observation period from 2008 to 2017, eight out of the total of 25 selected countries were efficient in terms of energy with a corresponding score of 1 such as France, Italy, Japan, Norway, Portugal, Sweden, the United Kingdom, and the United States. The average score of Germany was 0.96 (relatively efficient), while the average scores of other countries were lower than 1 and ranged from the lowest of 0.17 (India) to 0.84 (the Netherlands). India had the lowest efficiency for all of the 10 observed years with a score under 0.2 , followed by China and Indonesia with average scores around 0.2 .

By examining the separate years, it can be seen that some countries were efficient for several years from 2008 to 2017 such as Brazil, Belgium, Malaysia, Romania, and the Netherlands. On average, the efficiency scores of these countries for the whole period of 2008-2017 were lower than 1; however; these countries did have an efficiency score of 1 for at least one or more than one year. Other countries suffered a poor efficiency score for all of the 10 observed years.

Table 1. Energy efficiency score during 2008-2017.

\begin{tabular}{|c|c|c|c|c|c|c|c|c|c|c|c|}
\hline Countries & 2008 & 2009 & 2010 & 2011 & 2012 & 2013 & 2014 & 2015 & 2016 & 2017 & Average \\
\hline Belgium & 0.73 & 0.64 & 0.65 & 0.67 & 0.73 & 1.00 & 0.73 & 0.66 & 0.63 & 0.64 & 0.71 \\
\hline Brazil & 0.66 & 0.64 & 0.64 & 0.57 & 0.56 & 0.54 & 0.51 & 0.53 & 1.00 & 1.00 & 0.67 \\
\hline Canada & 0.62 & 0.61 & 0.62 & 0.60 & 0.60 & 0.60 & 0.61 & 0.63 & 0.63 & 0.61 & 0.61 \\
\hline China & 0.20 & 0.18 & 0.19 & 0.18 & 0.19 & 0.20 & 0.21 & 0.22 & 0.22 & 0.23 & 0.20 \\
\hline Czech Republic & 0.60 & 0.62 & 0.60 & 0.57 & 0.55 & 0.54 & 0.54 & 0.55 & 0.55 & 0.57 & 0.57 \\
\hline France & 1.00 & 1.00 & 1.00 & 1.00 & 1.00 & 1.00 & 1.00 & 1.00 & 1.00 & 1.00 & 1.00 \\
\hline Germany & 0.90 & 0.89 & 0.90 & 0.91 & 1.00 & 1.00 & 1.00 & 1.00 & 1.00 & 1.00 & 0.96 \\
\hline India & 0.17 & 0.15 & 0.16 & 0.15 & 0.16 & 0.17 & 0.17 & 0.18 & 0.19 & 0.19 & 0.17 \\
\hline Indonesia & 0.31 & 0.21 & 0.22 & 0.23 & 0.23 & 0.24 & 0.23 & 0.24 & 0.24 & 0.24 & 0.24 \\
\hline Italy & 1.00 & 1.00 & 1.00 & 1.00 & 1.00 & 1.00 & 1.00 & 1.00 & 1.00 & 1.00 & 1.00 \\
\hline Japan & 1.00 & 1.00 & 1.00 & 1.00 & 1.00 & 1.00 & 1.00 & 1.00 & 1.00 & 1.00 & 1.00 \\
\hline Korea, Rep. & 0.35 & 0.35 & 0.36 & 0.34 & 0.35 & 0.36 & 0.36 & 0.36 & 0.35 & 0.33 & 0.35 \\
\hline Malaysia & 1.00 & 1.00 & 1.00 & 0.38 & 0.34 & 0.33 & 0.33 & 0.34 & 0.34 & 0.35 & 0.54 \\
\hline Mexico & 0.39 & 0.37 & 0.39 & 0.37 & 0.38 & 0.39 & 0.39 & 0.40 & 0.40 & 0.40 & 0.39 \\
\hline Netherlands & 0.80 & 0.77 & 0.77 & 0.80 & 1.00 & 1.00 & 1.00 & 0.73 & 0.78 & 0.75 & 0.84 \\
\hline Norway & 1.00 & 1.00 & 1.00 & 1.00 & 1.00 & 1.00 & 1.00 & 1.00 & 1.00 & 1.00 & 1.00 \\
\hline Poland & 0.40 & 0.42 & 0.42 & 0.38 & 0.41 & 0.43 & 0.41 & 0.41 & 0.43 & 0.43 & 0.41 \\
\hline Portugal & 1.00 & 1.00 & 1.00 & 1.00 & 1.00 & 1.00 & 1.00 & 1.00 & 1.00 & 1.00 & 1.00 \\
\hline Romania & 0.52 & 1.00 & 1.00 & 0.51 & 0.49 & 0.51 & 0.52 & 0.54 & 0.55 & 0.57 & 0.62 \\
\hline Spain & 0.71 & 0.73 & 0.75 & 0.73 & 0.75 & 0.78 & 0.75 & 0.72 & 0.72 & 0.69 & 0.73 \\
\hline Sweden & 1.00 & 1.00 & 1.00 & 1.00 & 1.00 & 1.00 & 1.00 & 1.00 & 1.00 & 1.00 & 1.00 \\
\hline Thailand & 0.30 & 0.34 & 0.34 & 0.27 & 0.25 & 0.25 & 0.27 & 0.28 & 0.31 & 0.30 & 0.29 \\
\hline Turkey & 0.43 & 0.43 & 0.45 & 0.41 & 0.44 & 0.46 & 0.44 & 0.44 & 0.42 & 0.41 & 0.43 \\
\hline $\begin{array}{l}\text { United } \\
\text { Kingdom }\end{array}$ & 1.00 & 1.00 & 1.00 & 1.00 & 1.00 & 1.00 & 1.00 & 1.00 & 1.00 & 1.00 & 1.00 \\
\hline United States & 1.00 & 1.00 & 1.00 & 1.00 & 1.00 & 1.00 & 1.00 & 1.00 & 1.00 & 1.00 & 1.00 \\
\hline Average & 0.68 & 0.69 & 0.70 & 0.64 & 0.66 & 0.67 & 0.66 & 0.65 & 0.67 & 0.67 & 0.67 \\
\hline
\end{tabular}

The average score was the lowest in 2014 and reached its peak in 2008. The low efficiency scores were mainly caused by the excess of inputs. According to the analysis, for inefficient countries, 
there was no shortage in good outputs (GDP), but there was an excess mostly in labor forces and energy consumption as well as in $\mathrm{CO}_{2}$ emissions.

Taking China and India as examples, in 2017, China had a labor force of 790 million with a US $\$ 4795$ billion gross capital formation along with 3105 million tons of energy to create a GDP of US $\$ 10,161$ billion along with 9297 metric tons of $\mathrm{CO}_{2}$ emissions. Consequently, the efficiency score of China was 0.23 . The calculated excess for labor force, gross capital formation, and energy consumption were $87 \%, 53 \%$, and $66 \%$, respectively while the excess in $\mathrm{CO}_{2}$ emissions was approximately $73 \%$. To be efficient, China needs to reduce its excess in inputs and undesirable outputs. Regarding India, it had the lowest efficiency score of 0.17. In 2017, the GPD of India was US $\$ 2660$ billion while its $\mathrm{CO}_{2}$ emissions was 2234 metric tons and the total energy consumption in that year was around 933 million tons, causing an excess of $82.53 \%$ in energy used and $84.63 \%$ in $\mathrm{CO}_{2}$ emissions.

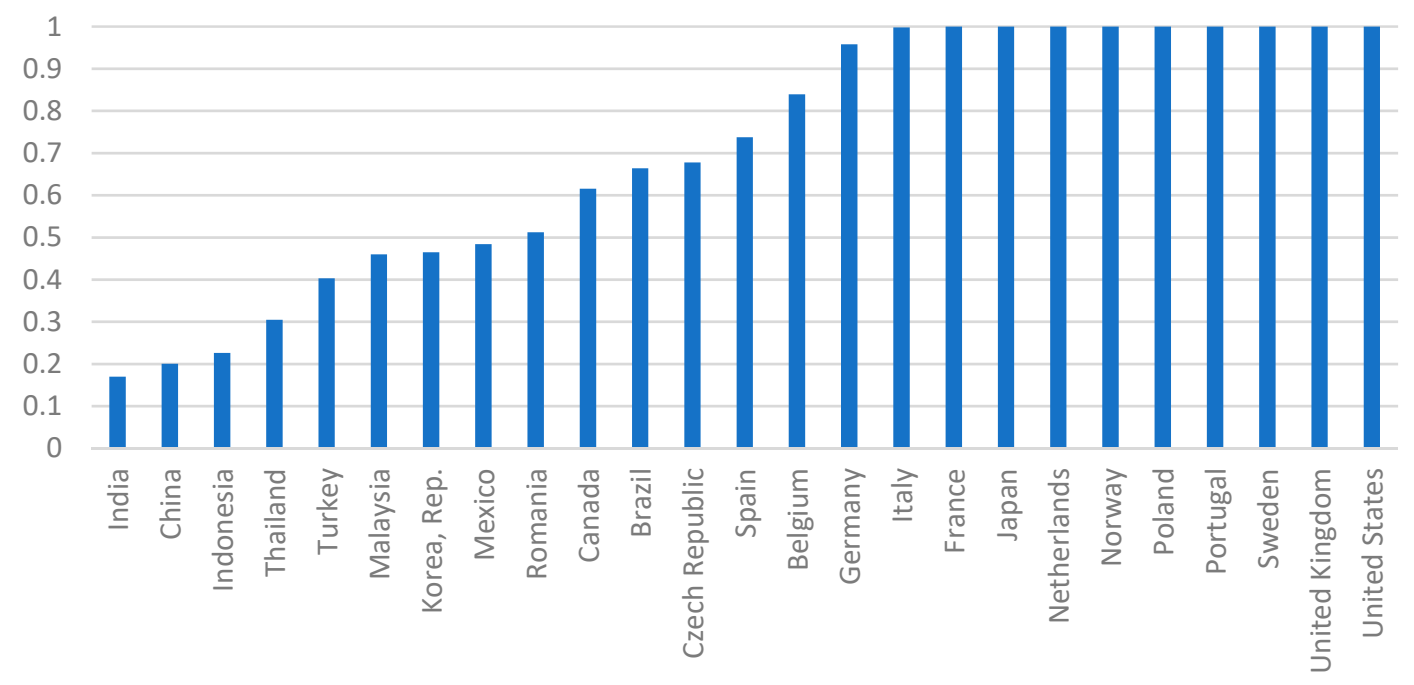

Figure 2. Average energy-efficiency by country from 2008 to 2017.

As observed, the efficiency scores of European countries are higher than those from the Americas and Asia. From 2008 to 2017, the average score of European countries was 0.81, while the average score of the Americas and Asia was 0.69 and 0.40, respectively as shown in Figure 3. The average efficiency scores of Asian countries remained stable with a very low score from 2008 to 2017. As observed, the average score was around 0.4. The low score was driven by China, India, and Indonesia, whose scores was around 0.2 and 0.3. Among the Asian countries, Japan was the only country that was efficient, thanks to the reduction in energy consumption during the observation period.

As illustrated in Figure 3, it is clear that there was a big gap between the average scores of Asia vs. the Americas and Europe. While European countries and the United States tried to reduce their amount of energy consumption, Asian countries such as China, India, and Indonesia have consumed more energy to achieve their economic development targets.

It is also worth noting that the average score of European countries slightly fluctuated with an up and down trend. However, the average score was quite stable and around 08. Of the 14 selected European countries, six countries were efficient with a corresponding score of 1 , while the score of two countries such as Germany was 0.96 . Among the European countries, Turkey had the lowest score (0.4), followed by the Czech Republic (0.57) and Romania (0.63). The average score of European countries remained stable during 2008-2017, which can be explained by the actions taken by the European Union, which has stressed the economic case for increasing resource efficiency including energy efficiency.

The average score of the countries from the Americas was stable during 2008-2015, then notably increased from 2016 to 2017. Among the selected countries from the Americas, two northern countries had higher scores than the two southern ones from 2008 to 2015. From 2008 to 2017, the United States was always efficient with a corresponding score of 1, while Canada and Mexico remained stable with 
average scores around 0.6 and 0.4 , respectively. Regarding the data in Table 2, the average score of Brazil fluctuated and ranged from 0.5 to 0.66 from 2008 to 2015, then rapidly increased to 1 over 2016-2017, which helped the average score of the Americas become higher in those two years and narrowed the distance with the average score of European countries.

As a whole observation, the average energy-efficiency score of 25 countries was around 0.67 during 2008-2017, illustrated in Figure 4.

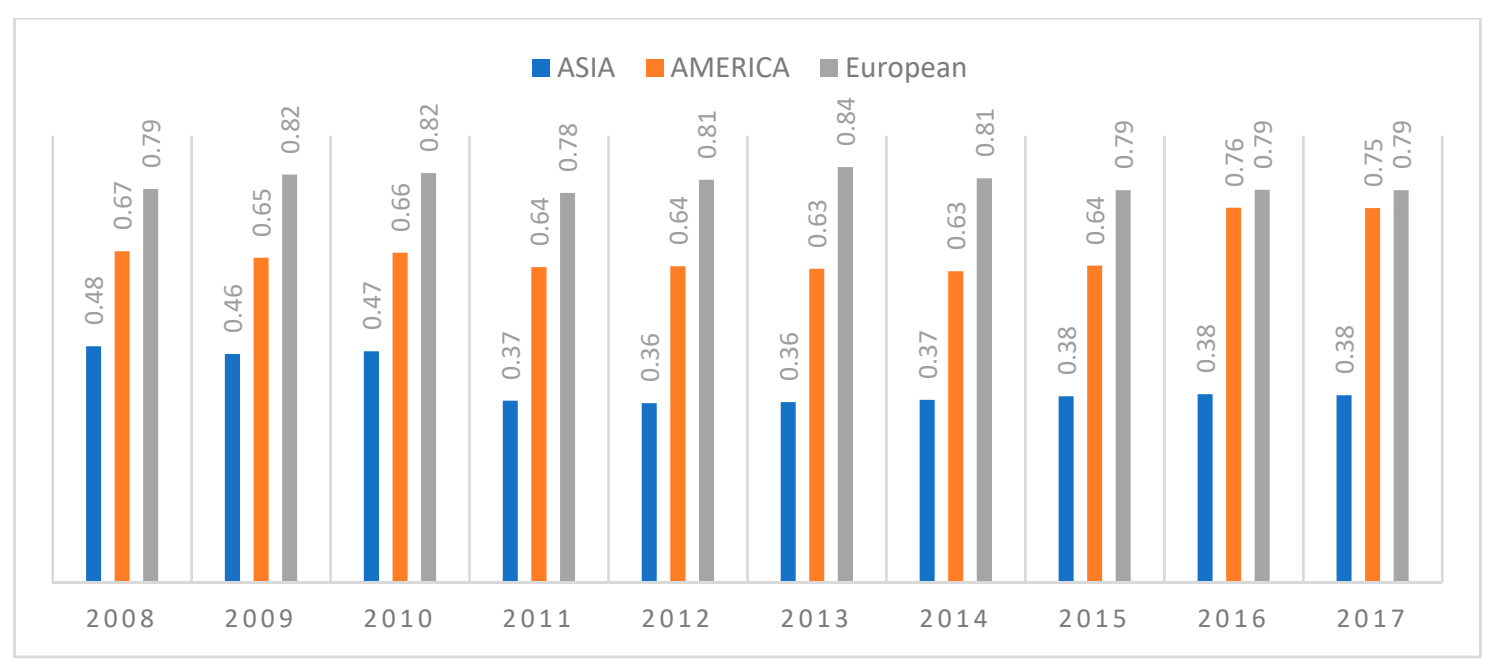

Figure 3. Energy efficiency of Europe, the Americas, and Asia from 2008 to 2017.

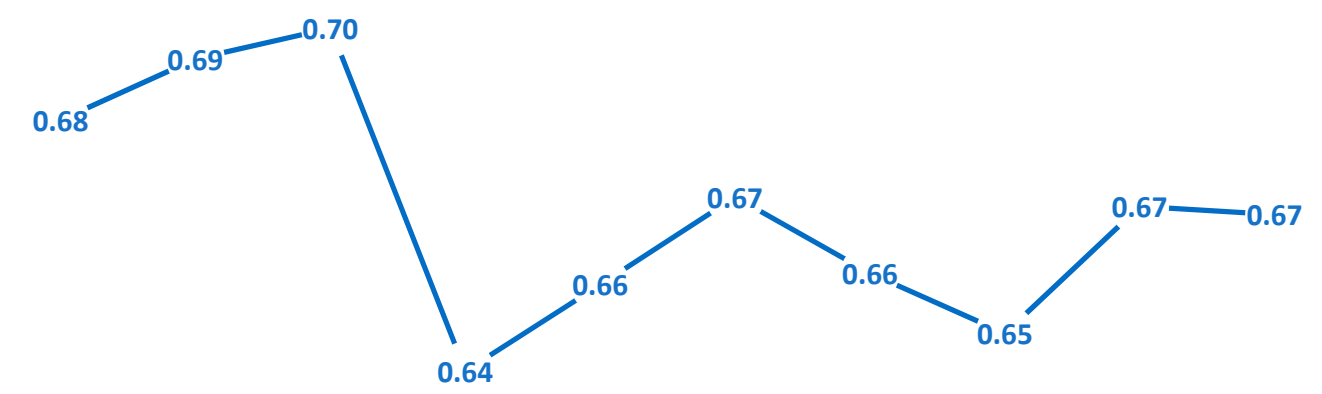

$\begin{array}{lllllllll}2008 & 2009 & 2010 & 2011 & 2012 & 2013 & 2014 & 2015 & 2016\end{array}$

Figure 4. Average energy-efficiency score of the 25 countries from 2008 to 2017.

\subsection{Forecasting Inputs and Output for 2018 to 2023}

In this stage, the grey model GM $(1,1)$ was employed to forecast the input and output data for the future period of 2018-2023 based on the data of the past period of 1990-2017. Then, the forecasted data were used to obtain the efficiency scores for the future period. However, before using the DEA to measure energy efficiency over the period 2018-2023, an accuracy test must be conducted to ensure that the forecasted data are reliable. Accuracy is controversial and of concern whenever a forecasting is produced since an error always exists. Therefore, this study measured the accuracy by using the mean absolute percent error (MAPE), which is applied commonly in many prediction studies. 
MAPE is the mean average absolute percent error that measures the accuracy in a fitted time series value in statistics, specifically trending [33].

$$
M A P E=\left(\frac{1}{n} \sum_{k=1}^{n}\left|\frac{x^{(0)}(k)-\hat{x}^{(0)}(k)}{x^{(0)}(k)}\right|\right) \times 100 \%
$$

where $n$ is the forecasting number of steps.

The parameters of the MAPE state the forecasting ability as follows:

- $\quad$ MAPE $<10 \%$ represents Excellent.

- $10 \%<$ MAPE $<20 \%$ is Good.

- $\quad 20 \%<\mathrm{MAPE}<50 \%$ is reasonable.

Table 2. Average mean absolute percent error (MAPE) of all DMUs.

\begin{tabular}{|c|c|c|c|c|c|c|}
\hline Countries & Labor Force & $\begin{array}{l}\text { Gross Capital } \\
\text { Formation }\end{array}$ & $\begin{array}{c}\text { Energy } \\
\text { Consumption }\end{array}$ & GDP & $\begin{array}{c}\mathrm{CO}_{2} \\
\text { Emissions }\end{array}$ & Average \\
\hline Belgium & $5.2 \%$ & $0.3 \%$ & $3.1 \%$ & $0.7 \%$ & $2.5 \%$ & $2.4 \%$ \\
\hline Brazil & $3.1 \%$ & $0.4 \%$ & $8.2 \%$ & $3.4 \%$ & $5.5 \%$ & $4.1 \%$ \\
\hline Canada & $3.7 \%$ & $0.1 \%$ & $4.7 \%$ & $0.8 \%$ & $7.8 \%$ & $3.4 \%$ \\
\hline China & $3.4 \%$ & $0.1 \%$ & $4.0 \%$ & $1.4 \%$ & $3.6 \%$ & $2.5 \%$ \\
\hline Czech Republic & $1.6 \%$ & $0.3 \%$ & $5.5 \%$ & $2.0 \%$ & $2.4 \%$ & $2.4 \%$ \\
\hline France & $1.0 \%$ & $0.2 \%$ & $2.8 \%$ & $0.7 \%$ & $2.4 \%$ & $1.4 \%$ \\
\hline Germany & $1.7 \%$ & $0.2 \%$ & $3.7 \%$ & $1.1 \%$ & $1.8 \%$ & $1.7 \%$ \\
\hline India & $1.0 \%$ & $0.8 \%$ & $3.9 \%$ & $0.8 \%$ & $1.5 \%$ & $1.6 \%$ \\
\hline Indonesia & $1.5 \%$ & $0.5 \%$ & $6.4 \%$ & $0.5 \%$ & $5.1 \%$ & $2.8 \%$ \\
\hline Italy & $2.2 \%$ & $0.5 \%$ & $5.9 \%$ & $1.5 \%$ & $2.6 \%$ & $2.5 \%$ \\
\hline Japan & $1.5 \%$ & $0.6 \%$ & $3.3 \%$ & $0.9 \%$ & $3.0 \%$ & $1.9 \%$ \\
\hline Korea, Rep. & $2.8 \%$ & $0.4 \%$ & $4.0 \%$ & $0.6 \%$ & $2.8 \%$ & $2.1 \%$ \\
\hline Malaysia & $1.5 \%$ & $1.0 \%$ & $3.7 \%$ & $0.9 \%$ & $2.3 \%$ & $1.9 \%$ \\
\hline Mexico & $1.8 \%$ & $0.4 \%$ & $2.6 \%$ & $1.1 \%$ & $1.8 \%$ & $1.5 \%$ \\
\hline Netherlands & $3.8 \%$ & $0.4 \%$ & $6.4 \%$ & $1.3 \%$ & $2.0 \%$ & $2.8 \%$ \\
\hline Norway & $2.1 \%$ & $0.5 \%$ & $3.3 \%$ & $0.7 \%$ & $2.3 \%$ & $1.8 \%$ \\
\hline Poland & $2.7 \%$ & $0.4 \%$ & $3.8 \%$ & $0.7 \%$ & $1.9 \%$ & $1.9 \%$ \\
\hline Portugal & $3.2 \%$ & $0.5 \%$ & $8.8 \%$ & $2.0 \%$ & $4.8 \%$ & $3.9 \%$ \\
\hline Romania & $1.6 \%$ & $0.5 \%$ & $6.2 \%$ & $3.4 \%$ & $4.8 \%$ & $3.3 \%$ \\
\hline Spain & $2.3 \%$ & $0.7 \%$ & $8.2 \%$ & $2.5 \%$ & $3.8 \%$ & $3.5 \%$ \\
\hline Sweden & $2.6 \%$ & $0.2 \%$ & $4.5 \%$ & $1.5 \%$ & $3.1 \%$ & $2.4 \%$ \\
\hline Thailand & $2.4 \%$ & $0.8 \%$ & $6.7 \%$ & $1.1 \%$ & $1.7 \%$ & $2.5 \%$ \\
\hline Turkey & $2.5 \%$ & $0.3 \%$ & $5.1 \%$ & $2.0 \%$ & $3.3 \%$ & $2.6 \%$ \\
\hline United Kingdom & $1.5 \%$ & $0.1 \%$ & $4.3 \%$ & $1.2 \%$ & $2.8 \%$ & $2.0 \%$ \\
\hline United States & $1.1 \%$ & $0.4 \%$ & $3.6 \%$ & $0.9 \%$ & $1.3 \%$ & $1.5 \%$ \\
\hline Average & $2.3 \%$ & $0.4 \%$ & $4.9 \%$ & $1.3 \%$ & $3.1 \%$ & $2.4 \%$ \\
\hline
\end{tabular}

The MAPE results are displayed in Table 2, which shows that the MAPE results of all inputs and outputs ranged from the lowest of $0.1 \%$ to the highest at $8.2 \%$ and the average MAPE of all inputs and outputs was $2.4 \%$. As the MAPE values obtained were all smaller than $10 \%$, it confirmed that the GM $(1,1)$ has good prediction accuracy in this research and that the forecasted data can be used in the further step of obtaining efficiency scores. 
The input "Total energy consumption" of Indonesia is used as an example to illustrate the generation of the forecast data. The sequence of raw data during 2008-2017 is as follows:

$$
\begin{gathered}
x^{(0)}=\left(x^{(0)}(1), \ldots, x^{(0)}(10)\right) \\
=(58.3,55.9,60.1,56.2,53.8,55.9,52.9,53.2,56.7,55.6)
\end{gathered}
$$

Simulate this sequence by respectively using the following three GM $(1,1)$ models and comparing the simulation accuracy:

From $x^{(0)}(k)+a x^{(1)}(k)=b$; compute the accumulation generation of $x^{(0)}$ as follows:

$$
x^{(1)}=\left(x^{(1)}(1), \ldots, x^{(1)}(n)\right)
$$

$$
=(58.3,114.2,174.3,230.5,284.3,340.2,391.1,446.3,503.0,558.6)
$$

In the next stage, the different equations of GM $(1,1)$ are created with the mean equation:

$$
\begin{aligned}
& z^{(1)}(2)=0.5(58.3+114.2)=86.22 \\
& z^{(1)}(10)=0.5(503+558.6)=530.8
\end{aligned}
$$

To continue, the values for coefficients $a$ and $b$ are found

$$
B=\left[\begin{array}{ll}
-116.3 & 1 \\
-127.3 & 1 \\
-228.4 & 1 \\
-284.5 & 1 \\
-340.5 & 1 \\
-396.6 & 1 \\
-452.6 & 1 \\
-508.7 & 1 \\
-564.8 & 1
\end{array}\right] \quad Y_{N}=\left[\begin{array}{l}
55.9 \\
60.1 \\
56.2 \\
53.8 \\
55.9 \\
52.9 \\
53.2 \\
56.7 \\
55.6
\end{array}\right]
$$

By using the least square estimation, we can obtain the sequence of parameters $[a, b]^{T}$ as follows:

$$
\hat{\mathrm{a}}=\left[\begin{array}{l}
\boldsymbol{a} \\
\boldsymbol{b}
\end{array}\right]=\left(B^{T} B\right)^{-1} B^{T} Y_{N}=\left[\begin{array}{l}
0.00548567 \\
57.4599547
\end{array}\right]
$$

Compute the simulated value of $x^{(0)}$, the original series according to the accumulated generating operation by using

$$
\begin{gathered}
\hat{x}^{(0)}(k+1)=\hat{x}^{(1)}(k+1)-\hat{x}^{(1)}(k) \\
=54.24(\text { forecasted for } 2018)
\end{gathered}
$$

The same was used to forecast the inputs and outputs of other countries over the period 2018-2023.

\subsection{Energy Efficiency from 2008 to 2017}

It was observed that during 2018-2023, the average efficiency score will be stable with a score of 0.68 . This stable trend can be applied for all observed countries as the score of the later years will remain relatively the same with the score for the previous years. Table 3 shows the forecasted efficiency over 2018-2023 along with a graphical illustration in Figure 5, which compares the scores in the past years and those for the future years.

As a whole, the average efficiency scores of the 25 countries over the period 2018-2023 will be low at 0.68 , with the number of efficient countries increasing to nine as one inefficient country in the past will become efficient 2018-2023 (Brazil). From the results, we also noted that the most inefficient 
countries will witness a lower energy-efficiency score in the future period of 2018-2023 when compared to those in the past period of 2008-2017. However, the change will be small and insignificant, as can be seen in Figure 5, except in the case of Brazil. The higher average efficiency score of Brazil can be explained by the faster growth of GPD than the growth of inputs and undesirable outputs.

Besides the nine efficient countries (Brazil, France, Italy, Japan, Norway, Portugal, Sweden, the United Kingdom, and the United States), the efficiency score of Germany will remain the same as its score over 2008-2017 (0.96), and nearly reach the efficiency frontier with a score ranging from 0.94 to 0.97 caused by around a $1.5 \%$ excess of labor force and approximately $2.3 \%$ redundancy in energy consumption leading to around a 3.5\% higher amount of $\mathrm{CO}_{2}$ emissions yearly from 2018 to 2023 . To be efficient in terms of energy, Germany should consider cutting down its energy and labor force.

Regarding inefficient countries, the average score over 2018-2023 will range from 0.19 to 0.79 . The lowest efficiency scores will be found in India (0.19), Indonesia (0.22), and China (0.26). It is noted that the efficiency of China from 2018 to 2023 was found to be higher than this during 2008-2017 with 0.26 for the former and 0.20 for the later, indicating its energy improvement, while the average score of Indonesia will decrease from 2018 to 2023, leading Indonesia to replace China as the second worst country in terms of energy efficiency.

Table 3. Efficiency scores from 2018 to 2023.

\begin{tabular}{|c|c|c|c|c|c|c|c|}
\hline Countries & 2018 & 2019 & 2020 & 2021 & 2022 & 2023 & Average \\
\hline Belgium & 0.77 & 0.77 & 0.76 & 0.75 & 0.75 & 0.74 & 0.76 \\
\hline Brazil & 1.00 & 1.00 & 1.00 & 1.00 & 1.00 & 1.00 & 1.00 \\
\hline Canada & 0.62 & 0.62 & 0.62 & 0.62 & 0.62 & 0.62 & 0.62 \\
\hline China & 0.25 & 0.25 & 0.26 & 0.27 & 0.27 & 0.28 & 0.26 \\
\hline Czech Republic & 0.62 & 0.63 & 0.63 & 0.64 & 0.64 & 0.65 & 0.64 \\
\hline France & 1.00 & 1.00 & 1.00 & 1.00 & 1.00 & 1.00 & 1.00 \\
\hline Germany & 0.97 & 0.97 & 0.96 & 0.96 & 0.95 & 0.94 & 0.96 \\
\hline India & 0.18 & 0.19 & 0.19 & 0.20 & 0.20 & 0.21 & 0.19 \\
\hline Indonesia & 0.23 & 0.22 & 0.22 & 0.22 & 0.21 & 0.21 & 0.22 \\
\hline Italy & 1.00 & 1.00 & 1.00 & 1.00 & 1.00 & 1.00 & 1.00 \\
\hline Japan & 1.00 & 1.00 & 1.00 & 1.00 & 1.00 & 1.00 & 1.00 \\
\hline Korea, Rep. & 0.36 & 0.36 & 0.36 & 0.36 & 0.37 & 0.37 & 0.36 \\
\hline Malaysia & 0.33 & 0.32 & 0.32 & 0.31 & 0.30 & 0.30 & 0.31 \\
\hline Mexico & 0.38 & 0.38 & 0.38 & 0.37 & 0.37 & 0.37 & 0.38 \\
\hline Netherlands & 0.79 & 0.79 & 0.79 & 0.79 & 0.79 & 0.79 & 0.79 \\
\hline Norway & 1.00 & 1.00 & 1.00 & 1.00 & 1.00 & 1.00 & 1.00 \\
\hline Poland & 0.43 & 0.43 & 0.44 & 0.44 & 0.44 & 0.44 & 0.44 \\
\hline Portugal & 1.00 & 1.00 & 1.00 & 1.00 & 1.00 & 1.00 & 1.00 \\
\hline Romania & 0.61 & 0.62 & 0.63 & 0.64 & 0.65 & 0.66 & 0.64 \\
\hline Spain & 0.68 & 0.68 & 0.67 & 0.67 & 0.66 & 0.66 & 0.67 \\
\hline Sweden & 1.00 & 1.00 & 1.00 & 1.00 & 1.00 & 1.00 & 1.00 \\
\hline Thailand & 0.30 & 0.30 & 0.30 & 0.30 & 0.30 & 0.30 & 0.30 \\
\hline Turkey & 0.41 & 0.41 & 0.40 & 0.40 & 0.40 & 0.40 & 0.40 \\
\hline United Kingdom & 1.00 & 1.00 & 1.00 & 1.00 & 1.00 & 1.00 & 1.00 \\
\hline United States & 1.00 & 1.00 & 1.00 & 1.00 & 1.00 & 1.00 & 1.00 \\
\hline Average & 0.68 & 0.68 & 0.68 & 0.68 & 0.68 & 0.68 & 0.68 \\
\hline
\end{tabular}


Additionally, by comparing the average efficiency of each country over two periods, it reveals that 10 countries (Belgium, Brazil, Canada, China, Czech Republic, India, Korea Republic, Poland, Romania, and Thailand) will experience an increase in efficiency while six countries will suffer the opposite trend (Indonesia, Malaysia, Mexico, the Netherlands, Spain, and Turkey).

By analyzing countries with an increase in their efficiency score, we found that the increase was caused by the faster growth of GDP despite the growing inputs. For example, in the case of China, in 2017, China had a labor force of 790 million with US $\$ 4795$ billion gross capital formation along with 3105 million tons of energy to create US \$10,161 billion in GDP, along with 9297 metric tons of $\mathrm{CO}_{2}$ emissions, where the calculated excess for labor forces, gross capital formation, and energy consumption were $87 \%, 53 \%$, and $66 \%$, respectively while the excess in $\mathrm{CO}_{2}$ emissions was approximately $73 \%$. However, in 2018, China had 821 million in labor (approximately 3.9\% higher than 2017) along with US $\$ 5425$ billion of gross capital formation and 3641 million tons of energy equally higher at $13.1 \%$ and $17.3 \%$, respectively, to generate a US $\$ 12,128$ billion in GDP and emit 11,367 metric tons of $\mathrm{CO}_{2}$ emission. Therefore, the excess in inputs will be $85.8 \%, 51.4 \%$, and $62.4 \%$ for labor force, gross capital formation, and energy consumption, respectively, while the redundancy in $\mathrm{CO}_{2}$ emissions will be $71.3 \%$.

Regarding the six countries with a decreasing efficiency score, we found that the faster growth in energy consumption was the main reason for most countries, with the exception of Turkey. In 2018, the total amount of energy consumed by Turkey decreased when compared to 2017; however, the significant increase in gross capital formation was the reason behind the lower score.

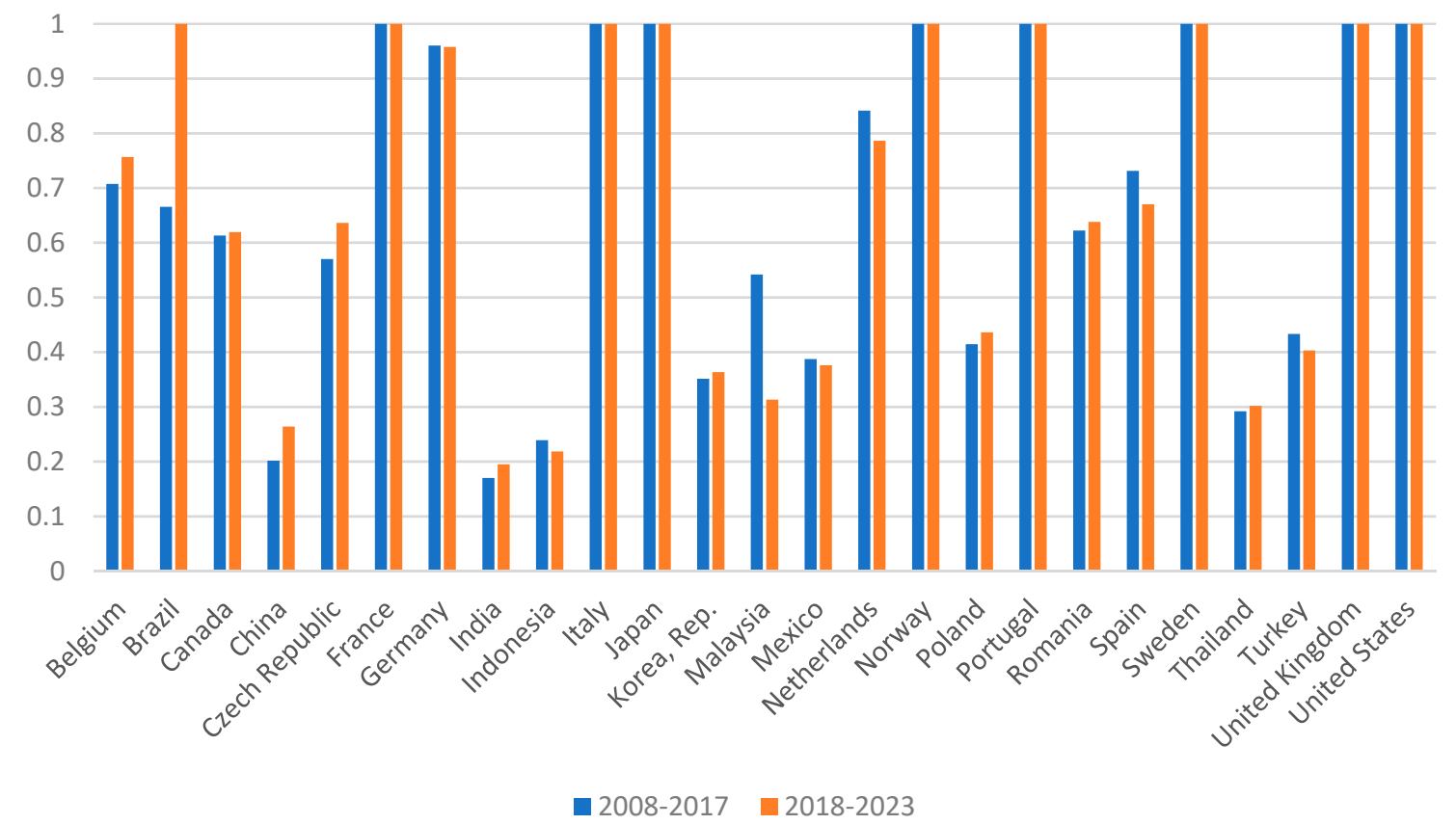

Figure 5. Energy-efficiency score from 2008 to 2017 vs. 2018 to 2023.

As above-mentioned, there is a large gap between the average score of European and countries in the Americans versus those of Asian countries from 2008 to 2017. This will not disappear during 2018-2023, as the average score of European, American, and Asian countries will be 0.81, 0.75, and 0.38, respectively. The gap between European countries and that of the Americas will be narrower while the gap between European and Asian countries will widen.

As shown in Figure 6, the average score of Asian countries will continue to be stable over the period 2018-2023 with the very low score of 0.38 driven by the poor score of all selected Asian countries with the exception of Japan. The score of these countries ranged from the lowest at 0.19 (India) to the highest at 0.36 (Republic of Korea). The average score of countries in the Americas will be higher 
thanks to the increase in Brazil and Canada, while the score for European countries will remain stable and unchanged.

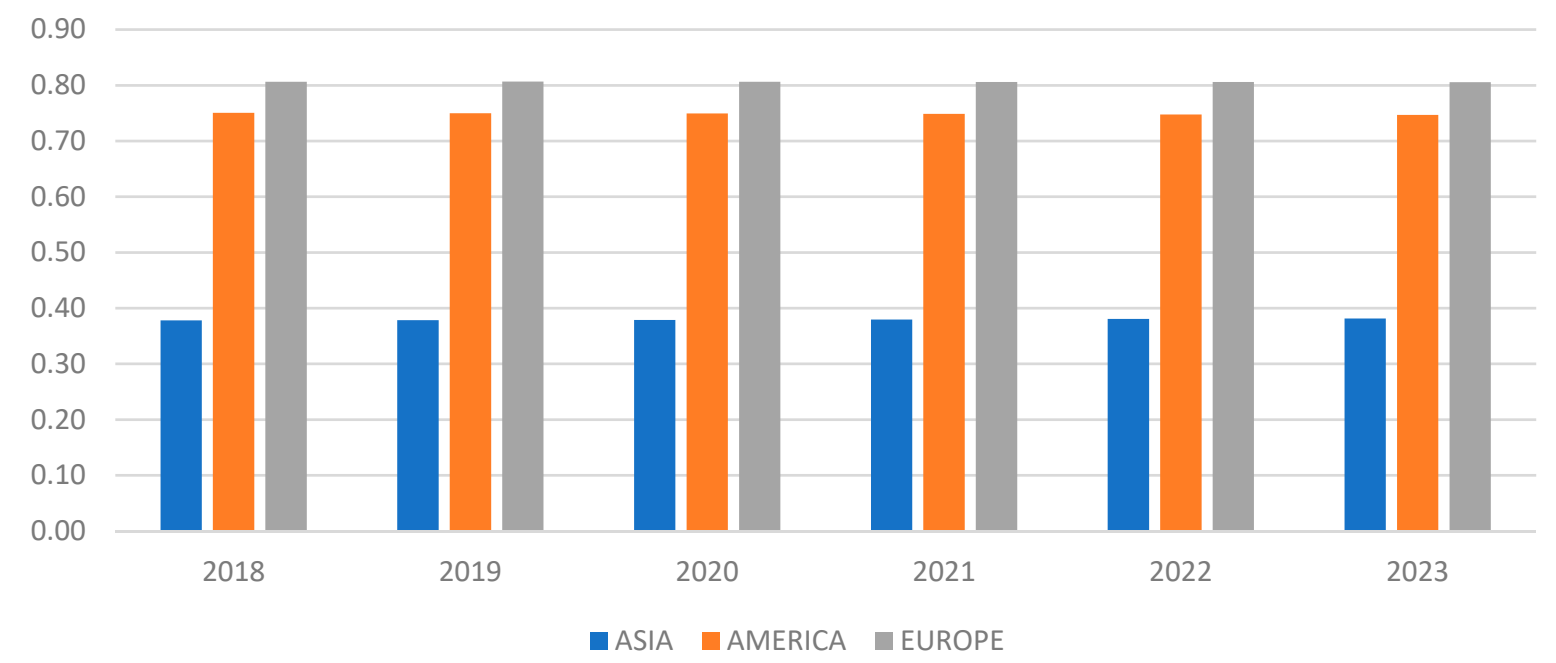

Figure 6. Efficiency score from 2018 to 2023.

\section{Discussions and Conclusions}

This paper focused on measuring and forecasting energy efficiency. First, the energy efficiency for 2008 to 2017 was analyzed, and the results at this stage revealed that the 25 selected countries showed an inefficiency in terms of energy. Of these 25 countries, eight countries were efficient during 2008-2017 and will continue to be efficient from 2018 to 2023 (France, Italy, Japan, Norway, Portugal, Sweden, the United Kingdom, and the United States), indicating the good balance between economic growth and environmental protection. Germany was the only inefficient country, with a very high score of 0.96 over the period 2008-2023, caused by an approximately $5 \%$ excess in energy consumption, leading to around $6.5 \%$ higher $\mathrm{CO}_{2}$ emissions. Additionally, Brazil was inefficient from 2008 to 2017, but will become efficient over the period 2018-2023.

The findings of this study also suggest higher energy-efficiency scores for European countries than those of countries from the Americas and Asia. The higher efficiency score of Europe is the result of constantly reducing the amount of energy consumption in most countries in Europe. On the other hand, the low score of Asian countries is the consequence of a higher demand of energy used in industries. Using more energy can accelerate the growth of economic development. However, more greenhouse gases have a negative impact on the environment. The United States, the second nation in terms of energy consumption, was always efficient due to its the high GDP and its reduction of energy consumption in recent years, while Canada had a score of around 0.6 to 0.7 , caused by the increasing energy demand due to climate change. Like Canada, the energy consumption of Brazil will continue to grow in future; however, thanks to the faster growth of GPD, while inefficient during 2008-2017, it will become efficient. However, consuming more energy to promote economic growth is not a sustainable solution.

The analyzed results found that the excess of total energy consumption was the main reason causing the energy inefficiency of most countries. Therefore, these countries should reconsider their energy infrastructure as well as reduce the amount of energy used in order to reach the efficiency-frontier. It was also observed that among the 25 countries, India suffered the lowest energy efficiency score, followed by China, Indonesia, and Thailand. The share of renewables in the total energy consumption of India and China ranges from $14 \%$ to $18 \%$, much higher than those of the United Kingdom, the United States, and Japan; however, the scores of these countries were still much lower than countries that have a moderate share of renewable energy. In fact, the increase in the use of renewable energy instead of unrenewable energy can help in reducing the greenhouse gases emitted into the environment, which works for every country, even China and India, as the huge and increasing amount of energy 
used in industrial zones in these countries is the main reason causing the inefficiency. Furthermore, the price of labor in these two countries is cheaper when compared to Europe and some countries in the Americas, causing a higher number in labor force, but lower productivity, which is the other reason for a low efficiency score. As observed, the total amount of energy used by China in 2017 was approximately 3105 metric tons and that for India was around 933 metric tons while the consumption of most European countries was less than 300 metric tons. Additionally, the total energy consumption of China and India increased year by year from 2014 to 2017 and will continue to grow from 2018 to 2023, while European countries showed a decrease in the amount of energy used year by year, not only during 2008-2017 but also during 2018-2023.

The results of this study also reveal that emerging countries such as China, India, Indonesia, Malaysia, Mexico, and Brazil had a low efficiency score from 2008 to 2009, which made these countries capture the great attention of policymakers. As indicated by the IEA [3], the efficiency gains in these emerging countries is the center of energy efficiency. However, by forecasting the performance of these countries over the period 2018-2023, the results found that with the exception of Brazil, other countries will not have significant efficiency gains without greater policy actions, as evidenced by the very low efficiency scores.

It is clear that implementing the right energy policies could help improve energy efficiency, which benefits in lowering the energy bell, improving air quality, reducing greenhouse gases, energy security, etc. By measuring and forecasting the energy efficiency of different countries, this study helps in not only sharing the understanding of the current status of how efficient different countries are in terms of energy, but also provides a clear picture for the future. Therefore, this study makes a core contribution to policymaking and strategy makers by providing useful and important information. Energy efficiency is pointed one of the most important criteria for sustainable development, therefore understanding and having an outlook for the future in this area are very helpful in considering the various policy strategies.

Author Contributions: C.-N.W. contributed to the research framework, checked, and revised draft paper; T.-D.N. collected the data and wrote the draft manuscript, checked, and revised the paper; M.-C.Y. supervised. All authors read and approved the final manuscript.

Funding: This research was partly supported by National Kaohsiung University of Science and Technology, and project number 108-2622-E-992-017-CC3 from the Ministry of Sciences and Technology in Taiwan.

Acknowledgments: The authors appreciate the support from National Kaohsiung University of Science andTechnology and Ministry of Sciences and Technology in Taiwan.

Conflicts of Interest: The authors declare no conflict of interest.

\section{References}

1. Barney, F.; Franzi, P. The Future of Energy from Future Dilemmas: Options to 2050 for Australia's Population, Technology, Resources and Environment; CSIRO Sustainable Ecosystems: Canberra, Australia, 2002; pp. 157-189.

2. EPA. Sources of Greenhouse Gas Emissions. Available online: https://www.epa.gov/ghgemissions/sourcesgreenhouse-gas-emissions (accessed on 10 May 2019).

3. IEA. Energy Efficiency 2018-Analysis and Outlook to 2040. Available online: https://www.iea.org/ efficiency2018/ (accessed on 10 May 2019).

4. Owusu, P.A.; Asumadu-Sarkodie, S. A review of renewable energy sources, sustainability issues and climate change mitigation. Cogent Eng. 2016, 3, 1167990. [CrossRef]

5. Fawcett, T.; Killip, G. Re-thinking energy efficiency in European policy: Practitioners' use of multiple benefits' arguments. J. Clean. Prod. 2018. [CrossRef]

6. Gomez-Calvet, R.G.; Conesa, D.; Gomez-Calvet, A.R.; Tortosa-Ausina, E. On the Dynamics of Environmental Performance in the European Union. Working Paper. 2014. Available online: https://ideas.repec.org/p/jau/ wpaper/2014-20.html (accessed on 8 October 2019).

7. Cornelis, E. History and prospect of voluntary agreements on industrial energy efficiency in Europe. Energy Policy 2019, 132, 5675-5682. [CrossRef]

8. Hu, J.L.; Honma, S. A Comparative Study of Energy Efficiency of OECD Countries: An Application of the Stochastic Frontier Analysis. Energy Procedia 2014, 61, 2280-2283. [CrossRef] 
9. Boroza, D. Technical and total factor energy efficiency of European regions: A two-stage approach. Energy 2018, 152, 5215-5232.

10. Rosenow, J.; Bayer, E. Cost and benefits of Energy Efficiency Obligations: A review of European programmes. Energy Policy 2017, 107, 53-62. [CrossRef]

11. Thonipara, A.; Runst, P.; Ochsner, C.; Bizer, K. Energy efficiency of residential buildings in Europe UnionAn exploratory analysis of cross-country consumption patterns. Energy Policy 2019, 129, 1156-1167. [CrossRef]

12. Marwwues, A.D.; Fuinhas, J.A.; Tomas, C. Energy efficiency and sustainable growth in industrial sectors in European Union countries: A nonlinear ARDL approach. J. Clean. Prod. 2019, 239, 118045.

13. Makridou, G.; Andriosopoulos, K.; Doumpos, M.; Zopounidis, C. Measuring the efficiency of energy-intensive industries across European countries. Energy Policy 2016, 88, 5735-5783. [CrossRef]

14. Gomez-Calvet, R.G.; Conesa, D.; Gomez-Calvet, A.R.; Tortosa-Ausina, E. Energy efficiency in the European Union: What can be learned from the joint application of directional distance functions and slacks-based measures? Appl. Energy 2014, 132, 137-154. [CrossRef]

15. Cucchilla, F.; D'Adamo, I.; Gastaldi, M.; Miliacca, M. efficiency and allocation of emission allowances and energy consumption over more sustainable European economies. J. Clean. Prod. 2018, 182, 805-817. [CrossRef]

16. Vieites, E.; Vassileva, I.; Arias, J.E. European Initiatives Towards Improving the Energy Efficiency in Existing and Historic Buildings. Energy Procedia 2015, 75, 1679-1685. [CrossRef]

17. Yang, T.; Chen, W.; Zhou, K.; Ren, M. Regional energy efficiency evaluation in China: A super efficiency slack-based measure model with undesirable outputs. J. Clean. Prod. 2018, 198, 859-866. [CrossRef]

18. Yu, J.; Zhou, K.; Yang, S. Regional heterogeneity of China's energy efficiency in "new normal": A meta-frontier Super-SBM analysis. Energy Policy 2019, 134, 110941. [CrossRef]

19. Lin, B.; Zhang, G. Energy efficiency of Chinese service sector and its regional differences. J. Clean. Prod. 2017, 168, 614-625. [CrossRef]

20. Feng, C.; Wang, M. Analysis of energy efficiency and energy savings potential in China's provincial industrial sectors. J. Clean. Prod. 2017, 164, 15311-15541. [CrossRef]

21. Yang, L.; Wang, K.L.; Geng, J.C. China's regional ecological energy efficiency and energy saving and pollution abatement potentials: An empirical analysis using epsilon-based measure model. J. Clean. Prod. 2018, 194, 3003-3008. [CrossRef]

22. Zhou, D.Q.; Meng, F.Y.; Bai, Y.; Cai, S.Q. Energy efficiency and congestion assessment with energy mix effect: The case of APEC countries. J. Clean. Prod. 2017, 142, 819-828. [CrossRef]

23. Guo, X.; Lu, C.C.; Lee, J.H.; Chiu, Y.H. Applying the dynamic DEA model to evaluate the energy efficiency of OECD countries and China. Energy 2017, 134, 392-399. [CrossRef]

24. Zhang, X.P.; Cheng, X.M.; Yuan, J.H.; Gao, X.J. Total-factor energy efficiency in developing countries. Energy Policy 2011, 39, 6446-6450. [CrossRef]

25. Pang, Z.F.; Deng, Z.Q.; Hu, J.L. Clean energy use and total-factor efficiencies: An international comparison. Renew. Sustain. Energy Rev. 2015, 52, 1158-1171. [CrossRef]

26. Wang, C.N.; Ho, T.H.X.; Hsueh, M.H. An Integrated Approach for Estimating the Energy Efficiency of Seventeen Countries. Energies 2017, 10, 1597. [CrossRef]

27. Wang, L.W.; Le, K.D.; Nguyen, T.D. Assessment of the Energy Efficiency Improvement of Twenty-Five Countries: A DEA Approach. Energies 2019, 12, 1535. [CrossRef]

28. Deng, J. Introduction to grey system theory. J. Grey Syst. 1989, 1, 12-14.

29. Tone, K. A slacks-based measure of efficiency in data envelopment analysis. Eur. J. Oper. Res. 2001, 130, 498-509. [CrossRef]

30. Tone, K. A slacks-based measure of super-efficiency in data envelopment analysis. Eur. J. Oper. Res. 2002, 143, 32-41. [CrossRef]

31. Enerdata Yearbook. Available online: https://yearbook.enerdata.net (accessed on 5 April 2019).

32. The World Bank. Available online: https://data.worldbank.org (accessed on 5 April 2019).

33. Deng, J.L. Control problems of grey systems. Syst. Control Lett. 1982, 1, 288-294.

(C) 2019 by the authors. Licensee MDPI, Basel, Switzerland. This article is an open access article distributed under the terms and conditions of the Creative Commons Attribution (CC BY) license (http://creativecommons.org/licenses/by/4.0/). 